\title{
Understanding Substance Abuse: Conceptual Models, Education and Training
}

\author{
Jackson de Carvalho, PhD \\ Associate Professor \\ Prairie View A \& M University \\ Prairie View, Texas 77446 \\ United States of America \\ Darron Garner, PhD \\ Department Head for Human Services \\ Alvin Community College \\ Houston, Texas 77511 \\ United States of America
}

\begin{abstract}
Substance abuse is one of the most serious threats facing the current American society. Approximately $25 \%$ of the Americanpopulation will have an alcohol or drug disorder at some point in life, afflicting individuals of every age, gender, race, and social status. The disorder can destroy the physical and mental health of the abuser, simultaneously deteriorating their families, relationships, andultimately their lives. The American Psychiatric Association (2018) defines a substance as a drug that is abused, such as, alcohol, cannabis, cocaine, an inhalant or a medication (e.g. a sedative, anxiolytic, or a toxin that can produce harmful effects when ingested or otherwise taken into the body). Misuse is defined as the act of using a substance in a manner that causes detrimental effects in some area of the individual's life. The purpose of this study is to explore the main models regarding the etiology and treatment of substance abuse.
\end{abstract}

Keywords: Substance abuse, conceptual models, stigma, education and training

\subsection{Introduction}

Individuals who abuse substances crowd our court systems and overpopulate our prisons (Van Wormer \& Davis, 2007; Walter \& Kowalczyk, 2012). It is the culprit in most assaults and homicides, incest, college date rapes, and campus racial incidents. Substance abuse is one of the most serious threats facing the current American society. The Addiction Center (2017) defines a substance as a drug that is abused, such as, alcohol, cannabis, cocaine, an inhalant or a medication (e.g. a sedative, anxiolytic, or a toxin that can produce harmful effects when ingested or otherwise taken into the body). Misuse is defined as the act of using a substance in a manner that causes detrimental effects in some area of the individual's life (Daley \& Marlatt, 2006; National Institute of Health, 2016).

This study will provide a review of existing conceptualizations regarding substance abuse, with an emphasis on the lack of consensus between the mental health and substance abuse fields as to the exact nature and course of treatment for substance abuse. The concept of stigma will be discussed and how it manifests itself into practitioner's perceptions towards individuals who abuse substances. Literary evidence will be provided which demonstrates how substance abuse training and education remain severely lacking,despite the need for and the positive impact it has upon practitioners.

Furthermore, this study is an attempt to expand the current knowledge base concerning practitioners' attitudes towards other substances of abuse in addition to alcohol and to explore the contribution of training, clinical experience, and other personal attributes to these attitudes. The information will provide a better understanding of the practitioners who assess and provide treatment for substance abuse disorders as a routine part of their clinical activities. It may illustrate the deleterious lack of substance abuse training among practitioners. It may highlight the negative attitudes and biases towards providing substance abuse treatment. Finally, it is anticipated that the information will prompt practitioners to expand their knowledge of substance abuse treatment approaches by eliciting their interest in either substance abuse certification or substance-related continuing education credits. This will serve to improve the quantity and quality of substance abuse treatment. 


\subsection{Literature Review}

One in four Americans will have an alcohol or drug disorder at some point in life, afflicting individuals of every age, gender, race, and social status (Stamm, Frick, \& Mackey, 2016). The disorder can destroy the physical and mental health of the abuser, simultaneously deteriorating their families, relationships, and careers (Van Wormer \& Davis, 2007). Substance abuse is responsible each year in America for approximately 600,000 deaths (Rettner, 2015). Forty million more suffer illnesses and injuries from the destructive effects of substance abuse. According to the National Highway Traffic Safety Administration, there were 14,470 deaths in 2016 involving drivers and motorcycle operators with blood alcohol levels of .08 or higher.

The overall number of deaths involving drivers and motorcycle operators with any amount of alcohol in their blood was 17,602. Approximately another 50,000 people suffered disabling and debilitating injuries in alcohol-related crashes. According to Levola, Kaskela, Holopainen, Sabariego, Tourunen, Cieza, and Pitkänen (2014), substance abuse can have harmful effects on the cardiovascular system, ranging from abnormal heart rates to heart attacks. Injection drug use can also lead to cardiovascular problems such as collapsed veins and bacterial infections of the blood vessels and heart valves. Substance abuse can lead to a variety of respiratory, gastrointestinal, and musculoskeletal problems and may lead to significant damage to the liver and kidneys (Center for Disease Control, 2015; Stamm et al., 2016).

Drug abuse not only weakens the immune system but is also linked to risky behaviors like needle sharing and unsafe sex. The combination greatly increases the likelihood of acquiring HIV-AIDS, hepatitis, and many other infectious diseases (CDC, 2015). Individuals who abuse substances crowd our court systems and overpopulate our prisons (Cropp, 2012; Martin, Conger, Sitnick, Masarik, Forbes, \& Shaw, 2014). It is the culprit in most assaults and homicides, incest, college date rapes, and campus racial incidents. According to the CDC (2015), approximately 68$80 \%$ of the current adult inmate population in the United States can associate their crime in some way to substance abuse. Close to 1.8 million prisoners are either arrested for violating the alcohol and drug laws, are intoxicated or high at the time of their offense or committed the crime merely to get the money to purchase the substance (CDC, 2015; Jayne \& Valentine, 2016).

Substance abuse plays a major role in societal problems such as teenage pregnancy. Of all the adults in homeless shelters, almost $90 \%$ abuse alcohol and more than $60 \%$ abuse illicit and/or prescription drugs (Addiction Center, 2017). Substance abuse significantly contributes to family dysfunction and divorce (AC, 2017). According to the National Institutes of Health (2016), approximately $70 \%$ of child abuse and neglect are related to substance-abusing parents. More than 500,000 children are in foster care largely due to parental substance abuse. Alcohol is implicated in most incidents of domestic violence (Mason, Zaharakis, \&Benotsch, 2014). Fear and uncertainty as well as financial pressures are felt by family members since substance abusers are more likely to change jobs regularly, to be unemployed for long periods of time, and to suffer injuries on the job (Koehn \&Cutcliffe, 2012).

The problem of substance abuse is exacerbated with the lack of education and training practitioners receive in their graduate programs concerning substance abuse. The research study of Becker (2013), found that the level of substance abuse education and training participants received in their doctoral programs was limited: $39.7 \%$ of the participants in Beck's study indicated no graduate training in which substance abuse was a topic and $87 \%$ of the participants received less hours than the equivalent of one semester of graduate coursework. Additionally, mostof the participants agreed to only two out of seven disease model statements. There were four out of seven eclectic model statements that most participants agreed. With regard to thepsychosocial model, all psychosocial statements were agreed to by the majority of the participants. Chi-square analyses showed that workshop/in-service hours, substance abuse caseload percentage, and family history of substance abuse were associated with differences in participants' conceptualizations regarding substance abuse.

\subsection{Etiological Models}

According to Mason and Spoth (2012), substance abuse is a very complex phenomenon. The history of substance abuse is full of controversy over its etiology, ranging from assertions of character or personality disorders to its being a disease. Numerous models exist regarding the etiology and treatment of substance abuse. Martin, Langenbucher, Chung \& Sher (2014) noted that the cause of substance abuse has been variously ascribed in the literature as (a) personal choice (moral model), (b) pharmacological properties of the drug (temperance model), (c) biological abnormalities (medical/disease model), (d) environmental processes (social learning model), (e) personality deficits (psychoanalytic model), and (f) family dynamics (family systems model). These models are explained below. 


\subsection{Moral Model}

This perspective views substance abuse as deviant behavior and willful misconduct. In this context, our legal system is a proponent of this model. For example, drunk driving is seen as a willful violation of societal norms and rules. Regardless of whether substance abuse is seen as a criminal or spiritual issue, this model emphasizes personal choice as the cause of substance abuse problems. The individual is seen as choosing to use alcohol or drugs, and that to overcome the substance abuse problem, the individual must simply choose to stop (Mangus,Kubal, Fridell, Pena, Frost, \& Joseph, 2015; Mason, Zaharakis, \&Benotsch2014).

\subsection{Temperance Model}

The moral perspective gave rise to the Temperance Movement of the late nineteenth century. Proponents of this movement regarded alcohol as an inherently addicting substance with destructive pharmacological properties (NIH, 2016; Roizen, 2004). They believed the only solution to the problem of alcohol abuse was to legislate it out of existence, strengthen character by moral preaching, and to influence future behavior by the threat of legal sanctions (Roizen, 2004). This movement was a collection of social, religious, and community groups, mainly the Women's Christian Temperance Union, The National Prohibition Party, and the Anti-Saloon League. These groups united into a national force and pressured and lobbied until Prohibition was passed (Jayne \& Valentine, 2016). As Levine (1984) writes, "liquor was a scapegoat in the classical sense of the term...something to be sacrificed in order to rid America of its major ills" (p. 111).

\subsection{Disease Model}

In the American Disease Model, substance abuse is seen as a disease: a syndrome of aberrant behaviors and physical symptoms (Edelman \&Fiellin, 2016; Mangus et al., 2015). Proponents of this model contend that substance abuseis a primarily a"chronic disease with genetic, psychosocial, and environmental factors influencing its development and manifestations. The disease is often progressive and fatal. It is characterized by continuous or periodic impaired control over drinking, preoccupation with the drug, use despite adverse consequences and distortions in thinking, most notable denial" (American Society of Addiction Medicine, 1994, pp. 123-124).

The alcoholic is not to be despised as bad but to be understood as a victim. The alcoholic is not morally weak but rather is seen as sick. Alcoholics have either an inborn or contracted biochemical disorder that renders them unable to control their drinking effectively. The present emphasis on substance abuse as a disease was born in the 1930s with the rise of the Fellowship of Alcoholics Anonymous (AA) and with the Twenty-first Amendment to the Constitution (Repeal of Prohibition; Crowley, \& Kirschner, 2015). The disease model provides the foundation for the 12-step treatment approaches such as Alcoholics Anonymous (AA) and other treatment programs where substance abusers are victims of a progressive illness that renders them incapable of using a substance in moderation. Although the disease is irreversible and incurable, its progression can be arrested through complete lifelong abstinence (Edelman \&Fiellin, 2016).

\subsection{Psychosocial Models}

In the 1970s, social scientists began to put forth alternative ways of looking at the growing problem of substance disorders. They proposed viewing them not as unitary disorders defined in terms of a single disease label, but as acquired habits based on a range of environmental and cognitive factors (Bahrke, 2012; Peele, 1984). Since this time, models of understanding the etiology of substance disorders have emerged, such as (a) conditioning, (b) social learning, (c) cognitive, (d) psychoanalytic, (e) developmental, and (f) family system factors.

The premise of the conditioning/behavioral model is that alcoholics or addicts continue to use despite problems related to their use because the consumption is perceived to induce pleasure, remove discomfort, enable and enhance social interactions, generate feelings of power and "drown" unpleasant memories. This model maintains the belief that if substance use leads to rewarding consequences, it is likely to continue or increase, ultimately becoming a learned habit (Bahrke, 2012; Miller \& Hester, 2003).

Proponents of the social learning model focus on the influence of one's social environment on behavior. They attribute the cause of substance abuse to inappropriate role models, peer pressure, and environmental aspects that promote substance use (Miller \& Hester, 2003). The relapse prevention (RP) treatment approach is based on the premise of the social learning model. This approach assumes a combination of many different high-risk interpersonal, intrapersonal, and lifestyle factors contribute to a lapse or relapse (Edelman et al., 2016; Jayne \& Valentine, 2016; Witkiewitz, 2005).

The cognitive and cognitive-behavioral models are also subsets of the behavior model. The cognitive model believes the cause of substance abuse lies mainly in non-realistic and irrational belief systems (NIH 2016) and is based on the premise that thoughts influence behaviors and emotions and that such irrational beliefs can be brought to awareness and changed, resulting in behavior change (Van Wormer \& Davis, 2007). 
Similarly, the cognitive-behaviorists posit that the triggers for substance abuse are life events and the accompanying beliefs about such events (Aikins, 2015; Winters \&Arria, 2011).

The psychoanalytic model views substance abuse as a symptom of a deeper personality problem related to unfulfilled needs during the early stages of development (CDC, 2015). The contemporary psychodynamic treatment approach is based upon the premise of this model. This approach contends that individuals with substance abuse disorders have a range of ego deficits and difficulties involving affect regulation and control. The model asserts that these deficits render the individual susceptible to substance abuse (Aikins, 2015).

Those who ascribe to the general/family systems model view an individual's behavior as performing a function within the context of a larger social/family system (CDC, 2015). Adhering to this model is the family therapy treatment approach. This method assumes that in order to fully understand the actions of the substance abuser, one needs to consider his or her relationship with other members in the family. What appears to be a substance abuse problem is actually a malfunctioning of the larger family system (Cooper, 2012; NIH, 2016).

\subsection{Public Health/Eclectic Model}

This model asserts that in order to understand and provide treatment for substance disorders, three causal factors need to be considered: agent, host, and environment (CDC, 2015). All of the previously described models focus on one of these causal factors, to the point of overlooking the other two. For example, the temperance model emphasizes the destructive power of the drug itself (agent). An emphasis on the individual abusing the substance (host) can be seen in the moral, medical/disease, and psychoanalytic models. The general/family systems, social learning, and conditioning models all focus on environmental factors (Cooper, 2012; NIH, 2016).

The public health model emphasizes the importance of considering and addressing all three elements. It utilizes a biopsychosocial approach to the prevention and treatment of substance abuse (CDC, 2015). According to van Wormer and Davis (2007), the public health model is a client-centered approach "compatible with the harm reduction model in that the overriding purpose is to help the client reduce the harm to himself or herself or others. Harm reduction therapy allows for creativity in the design of treatment strategies" (p. xv). The goal of the public health model is to reduce harm by encompassing a set of eclectic strategies to help people help themselves by moving from safer use to abstinence, if so desired (Cooper, 2012).

While every model would agree that substance abuse is treatable, there are those disease model proponents who assert it is nevertheless, a progressive and incurable disease. With regard to altering the course of addiction, mental health systems, particularly those from the cognitive-behavioral framework, typically promote the idea that individuals exert some control over their feelings, thoughts, and actions surrounding the course of their substance abuse. However, the medical model, particularly the 12-step ideology disseminates the notion that individuals have no control over their course. The first three steps of the 12-step model involve "admitting powerlessness" and that only "a power greater than ourselves" can restore those with a substance use disorder to sanity (AC, 2017; CDC, 2015; NIH, 2016).

\subsection{Stigma of Substance Abuse}

As evidenced above, there are numerous theories regarding the nature and treatment of substance abuse. The theoretical model utilized can impact the degree of stigma attached to substance abuse (AC, 2017). The notion that the degree of stigma attached to substance abuse is affected by the type of theoretical model utilized is supported in Goffman's (1963) model of stigma. Erving Goffman is widely credited for conceptualizing and creating a framework for studying stigma. According to Goffman, disorders associated with the highest degree of stigma share six common attributes: (a) disruptiveness; (b) peril; (c) origin; (d) course; (e) concealability; and (f) aesthetics. Disruptiveness level relates to interference with relationships and social interactions. Peril involves whether the condition will physically or socially damage others. The degree of disruption and peril that substance disorders create for the abusers, in addition to their family and society, is well-documented on the previous chapter. The remaining attributes are affected by the type of substance abuse model being utilized and are discussed below.

\subsection{Concealability}

Another common aspect of a stigma is concealability. Since there is a stigma associated with being an alcoholic or drug addict, many substance abusers choose to conceal their disorder. Alcoholics Anonymous instituted anonymity as primary to counter the stigma associated with alcoholism (AC, 2017; Aikins, 2015). Yet, as Califano (2007) offers, this appears to have had a paradoxical effect. Alcoholics Anonymous has helped weld this iron curtain of secrecy. Based on sincere beliefs that anonymity is essential for individuals to enter the program. In fact, this commitment to anonymity is also necessitated by the way society has treated this disease of body, mind, and spirit. The reluctance of employers to hire recovering alcoholics or drug addicts and the difficulty anyone who admits alcoholism or drug addiction has in obtaining health insurance encourage AA members to support secrecy as a sacred tenet of recovery. 
It is time for AA and its members to encourage those who are willing to come forward, like faces and voices of recovery, to speak about their experience. More openness from those in recovery "from alcohol and drug addiction will help many others confront their problem and help our society understand that this is a disease that millions are in recovery from" (p. 166)

Research shows that there is a paradoxical pattern of beliefs that exists among practitioners regarding the concept of substance abuse (AC, 2017; Edelman et al., 2016; Jayne \& Valentine, 2016; Stamm et al., 2016). Such attitudinal inconsistencies are demonstrated in the tendency to endorse substance abuse as a disease while at the same time seeing its use as a willful choice or even a moral failing. In a study by Roberts (1998), though approximately $73 \%$ of the 511 practitioners surveyed agreed alcoholism is a medical illness or disease, 58\% of the sample disagreed with the assertion "an alcoholic is as blameless for the illness as a diabetic." This indicates that most of the sample conceptualizes it as a disease while simultaneously assigning blame to the individual for their substance abuse problem, suggesting that a level of stigma remains attached to substance abuse even in clinical contexts. Fortunately, numerous studies (Becker, 2013;Edelman et al., 2016; Jayne \& Valentine, 2016) have demonstrated the positive impact substance abuse education and training has upon practitioners' attitudes towards its treatment.

\subsection{Aesthetics of Substance Abuse}

The aesthetics dimension is yet another element of a stigma. Aesthetics concerns how others react to the condition with disgust or dislike. The Big Book of AA has long documented the perception of alcoholics as a public nuisance and "social misfits" (Roizen, 2004). Substance abusers are often blamed for their condition and many people believe it could be avoided if individuals made better moral decisions. According to Califano (2007), the stigma remains that substance abusers who cannot control their drinking or drugging are deemed as morally weak and self-indulgent.

Clearly, substance abuse fits the profile of a condition that carries a high level of stigma. This stigma is exacerbated depending upon the treatment model being utilized. Goffman's (1963) explanation of stigma focuses on the public's attitude toward a person who possesses an attribute that falls short of societal expectations. Given Goffman's definition of stigma, it is clear that substance abuse is a highly stigmatized phenomenon that can affect and be affected by the attitudes of the therapist providing treatment. The implications of the stigma of substance abuse and the possible effects it has on practitioners' attitudes towards substance abuse is explored in the following section.

\subsection{Substance Abuse, Education and Training}

Several studies (Becker, 2013; Cox, Ketner, \& Blow, 2013; Edelman et al., 2016; Jayne \& Valentine, 2016; Stamm et al., 2016) correlate the level of substance abuse education with the practitioner's attitude toward substance abuse. Specifically, they found where substance abuse training and education are provided to practitioners, positive attitudes towards substance abusers ensue and practitioners became more optimistic regarding their treatment (Becker, 2013). Jayne \& Valentine (2016) found that health professional trainees who observed individuals achieve recovery from substance abuse had a more positive attitude towards providing for its treatment. Furthermore, Cox et al. (2013) revealed that trainees had an increased perception of competence to provide substance abuse treatment once training concluded. AC (2017) and NIH (2016) revealed that exposure to treatment programs improved health professionals' attitude scores. Sahker, Acion, and Arndt (2015) investigated the extent to which counselor level of training in the area of alcohol influenced successful client outcomes. The authors concluded that knowledge of substance abuse positively influenced counselor attitudes towards substance use disorders, counselor behaviors during the session, and counselor diagnosis, prognosis, and recommendations for the client.

\subsection{Implications for Practice}

Clearly, substance abuse education plays an insignificant role in the professional preparation of most practitioners. Becker (2013) and Stamm, Frick, \& Mackey (2016) stated that the inadequate training provided for clinical and counseling psychology students in these areas is linked to insufficient treatment for substance abuse problems and this reasonably applies today. According to Wechsler and Rochman(1982): Successful identification and treatment of alcohol related problems are contingent on the caregiver's willingness and ability to recognize and respond to problem drinkers. This response, however, can be encumbered by a lack of appropriate knowledge and skills, (p. 953).

The implication of inadequate training is that practitioners are often reluctant to identify, treat, or refer individuals with substance abuse concerns. Practitioners have often felt uncomfortable incorporating substance abuse assessment and treatment into their repertoire of clinical skills (Becker, 2013). As indicated by Miller and Brown (1997), practitioners have "too often lacked the specific training, encouragement, and confidence to treat these common disorders" (p. 1273). Clinical competence involves recognizing the many factors which complicate the diagnosis and treatment of substance abuse. Since symptoms of substance disorders may appear psychiatric in nature, a therapist's knowledge of specific symptoms associated with particular kinds of drug use is vital. 
Furthermore, individuals with substance use disorders are often not accurate reporters of their histories. Denial and/or lying to avoid detection are common (Miller \& Brown, 1997). Patients frequently present without awareness that their problems may be related to their substance abuse. The substance abuse component often becomes buried within a host of other problems. As a result, practitioners without substance abuse training disregard or dismiss the substance component of assessment (Becker, 2013).

Research suggests that over $25 \%$ of people presenting in clinical settings have diagnosable substance abuse disorders that are often hidden (Walter \& Kowalczyk, 2012). With an inadequately trained therapist, manifestations of substance abuse are often misdiagnosed or unrecognized and are left untreated (van Wormer \& Davis, 2007). This practice ultimately perpetuates the clients' denial and minimization of their addiction. Many opportunities for prevention and early intervention are missed and progress is hindered (Miller \& Brown, 1997; van Wormer \& Davis, 2007; Wall, BaileyShea, \& McIntosh, 2012).

\section{References}

Addiction Center (2017). College Drug Abuse. Addiction Center. Retrieved from: https://www.addictioncenter.com/college/

Aikins, R. D. (2015). From recreational to functional drug use: The evolution of drugs in American higher education, 1960-2014. History of Education, 44(1), 25-43. doi: 10.1080/0046760X.2014.979251.

American Psychiatric Association (2018). Diagnostic and statistical manual of mental disorders. Washington, DC: Author.

Bahrke, M. S. (2012). Performance-enhancing substance misuse in sport: Risk factors and considerations for success and failure in intervention programs. Substance Use \& Misuse, 47(1314), 1505-1516. doi: 10.3109/10826084.2012.705674.

Becker, S. J. (2013). Adolescent substance-abuse: National trends, consequences, and promising treatments. Brown University Child \& Adolescent Behavior Letter, 29(5), 1-7

Califano, J. A. (2007). High society: How substance abuse ravages America and what to do about it. New York: Public Affairs.

Centers for Disease Control (2015). Smoking and tobacco use. CDC. Retrieved from http:www.cdc.gov.

Cooper, L. (2012). Combined motivational interviewing and cognitive-behavioral therapy with older adult drug and alcohol abusers. Health \& Social Work, 37 (3),173-179. doi: 10.1093/hsw/hls023

Cox, R. B., Ketner, J. S., \& Blow, A. J. (2013). Working with couples and substanceabuse: Recommendations for clinical practice. American Journal of Family Therapy, 41(2), 160-172. doi:10.1080/01926187.2012.670608

Crowley, R. A., \& Kirschner, N. (2015). The integration of care for mental health, substance-abuse, and other behavioral health conditions into primary care: Executive summary of an American college ofphysicians' position paper. Annals of Internal Medicine, 163(4), 298-299. doi: 10.7326/M15- 0510

Cropp, D. (2012). The theory and practice of collaborations in law enforcement. International Journal of Police Science \& Management, 14(3), 213-218. doi: 10.1350/ijps.2012.14.3.284

Daley, D., \& Marlatt, G. A. (2006). Overcoming your alcohol or drug problem. New York: Oxford University Press.

Edelman, E. J., \&Fiellin, D. A. (2016). Alcohol use. Annals of Internal Medicine, 164(1), ITC1-16.

Goffman, E. (1963). Stigma: Notes on the management of spoiled identity. New Jersey: Prentice Hall.

Jayne, M., \& Valentine, G. (2016). Alcohol-related violence and disorder. Progress in Human Geography, 40(1), 67-87. doi: 10.1177/0309132514558445.

Koehn, C., \&Cutcliffe, J. R. (2012). The inspiration of hope in substance-abuse counseling. Journal of Humanistic Counseling, 51(1), 78-98.

Levine, H. G. (1984). The alcohol problem in America: From temperance to alcoholism. British Journal of Addiction, 79, 109-119.

Levola, J., Kaskela, T., Holopainen, A., Sabariego, C., Tourunen, J., Cieza, A., \&Pitkänen, T. (2014). Psychosocial difficulties in alcohol dependence: A systematic review of activity limitations and participation restrictions. Disability \& Rehabilitation, 36(15), 1227-1239. doi: 10.3109/09638288.2013.837104

Mangus, R. S., Kubal, C. A., Fridell, J. A., Pena, J. M., Frost, E. M., \& Joseph T. A. (2015). Alcohol abuse in deceased liver donors: Impact on post-transplant outcomes. Liver International, 35(1), 171-175.doi: 10.1111/liv.12484

Martin, M. J., Conger, R. D., Sitnick, S. L., Masarik, A. S., Forbes, E. E., \& Shaw, D. S. (2015). $\quad$ Reducing risk for substance use by economically disadvantaged young men: Positive family environments and pathways to educational attainment. Child Development, 86(6), 1719-1737. doi: 10.1111/cdev.12413 
Mason, W. A., \& Spoth, R. L. (2012). Sequence of alcohol involvement from early onset to young adult alcohol abuse: Differential predictors and moderation by family focused preventive intervention. Addiction, 107(12), 21372148. doi: 10.1111/j.1360-0443.2012.03987.x

Mason, M. J., Zaharakis, N., \& Benotsch, E. G. (2014). Social networks, substance use, and mental health in college students. Journal of American College Health, 62(7), 470-477. doi: 10.1080/07448481.2014.923428.

Miller, W. R., \& Brown, S. A. (1997). Why psychologists should treat alcohol and drug problems. American Psychologist, 52, 1269-1279.

Miller, W. R., \& Hester, R. K. (2003). Treating alcohol problems: Toward an informed eclecticism. In R. Hester \& W. Miller (Eds.), Handbook of alcoholism treatment approaches: Effective alternatives (3rd ed., p. 1-12). Boston: Allyn \& Bacon.

National Institutes of Health (2016). Drug facts-marijuana. National Institute on Drug Abuse. Retrieved from: https:www.drugabuse.govpublicationsdrugfactsmarijuana\#references.

Peele, S. (1984). The cultural context of psychological approaches to alcoholism. American Psychologist, 12, 13371351.

Rettner, R. (2015). Heroin overdose deaths nearly quadruple in 13 years. Live Science. Retrieved from: http:www.livescience.com50025-heroine-overdosedeaths-united-states.html

Roizen, R. (2004). How does the nation's "alcohol problem" change from era to era? In S. Tracy \& C. Acken (Eds.), Altering American consciousness: The history of alcohol and drug use in the United States, 1800-2000 (pp. 6187). Amherst: University of Massachusetts Press.

Sahker, E., Acion, L., \& Arndt, S. (2015). National analysis of differences among substance-abuse treatment outcomes: College student and nonstudent emerging adults. Journal of American College Health, 63(2), 118-124. doi: 10.1080/07448481.2014.990970

Stamm, M. E., Frick, W. C., \& Mackey, H. J. (2016). An analysis of U.S. student drug and alcohol policies through the lens of a professional ethic for school leadership. International Journal of Education Policy \& Leadership, $11(1), 1-22$.

Van Wormer, K., \& Davis, D. R. (2007). Addiction treatment: A strengths perspective. Belmont, CA: Thomson Brooks/Cole.

Wall, A. F., BaileyShea, C., \& McIntosh, S. (2012). Community college student alcohol use: Developing contextspecific evidence and prevention approaches. Community College Review, 40(1), 25-45. doi: $10.1177 / 0091552112437757$

Walter, G., \& Kowalczyk, J. (2012). The effectiveness of alcohol policies in 4-year public universities. Journal of Community Health, 37(2), 520-528. doi: 10.1007/s10900-011-9474-3.

Winters, K. C., \&Arria, A. (2011). Adolescent brain development and drugs. Prevention Researcher, 18(2), 21-24.

Wechsler, H., Rohman, M. (1982). Future caregivers' views on alcoholism treatment. Journal of Studies on Alcohol, 43, 939-954.

Witkiewitz, K. (2005). Defining relapse from a harm reduction perspective. Journal of Evidence Based Social Work, 2, 191-206 